\title{
Comprehensive Learning through the Multi-Disciplinary Design of an Automated Guided Vehicle
}

\author{
A. Aguilar-Gonzalez, Ph. D. ${ }^{1}$, R. C. Lozoya, Ph. D. ${ }^{1}$, L. Orona, M.Sc. ${ }^{1}$, S. Romo, MBA ${ }^{1}$, and A. Roman, Ph. D. ${ }^{1}$ \\ Tecnológico de Monterrey, Mexico, alberto.aguilar@itesm.mx, camilo.lozoya@itesm.mx, '.orona@itesm.mx, \\ s.romo@itesm.mx, armando.roman@itesm.mx
}

\begin{abstract}
Often, academic assignments for engineering courses include Project Oriented Learning (POL) as a method to evaluate the knowledge and skills that students acquired during a certain term. Also, educational institutions motivate their faculty to generate projects in which a real situation is involved. In other cases, educators design activities that integrate a multidisciplinary approach. However, conceiving and implementing a project which has these three characteristics is a difficult task. In this paper, a project which considers all three is presented, from the inception of the idea thru the implementation of the entire process. During one semester, students from diverse majors designed, built, and tested an autonomous vehicle to provide tours to prospective students and their parents. This project involves a multidisciplinary approach with undergraduates and faculty from four different areas: mechanics, mechatronics, industrial design, and computer science.

Keywords-Multidisciplinary projects, Automated Guided

Vehicle, higher education projects.
\end{abstract}

Digital Object Identifier (DOI):

http://dx.doi.org/10.18687/LACCEI2016.1.1.380

ISBN: 978-0-9822896-9-3

ISSN: 2414-6390

$14^{\text {th }}$ LACCEI International Multi-Conference for Engineering, Education, and Technology: "Engineering Innovations for Global Sustainability", 20-22 July 2016, San José, Costa Rica. 


\title{
Comprehensive Learning through the Multi-Disciplinary Design of an Automated Guided Vehicle
}

\author{
A. Aguilar-Gonzalez, Ph. D. ${ }^{1}$, R. C. Lozoya, Ph. D. ${ }^{1}$, L. Orona, M.Sc. ${ }^{1}$, S. Romo, MBA ${ }^{1}$, and A. Roman, Ph. D. ${ }^{1}$
}

${ }^{1}$ Tecnológico de Monterrey, Mexico, alberto.aguilar@itesm.mx, camilo.lozoya@itesm.mx, l.orona@itesm.mx, s.romo@itesm.mx, armando.roman@itesm.mx

\begin{abstract}
Often, academic assignments for engineering courses include Project Oriented Learning (POL) as a method to evaluate the knowledge and skills that students acquired during a certain term. Also, educational institutions motivate their faculty to generate projects in which a real situation is involved. In other cases, educators design activities that integrate a multidisciplinary approach. However, conceiving and implementing a project which has these three characteristics is a difficult task. In this paper, a project which considers all three is presented, from the inception of the idea thru the implementation of the entire process. During one semester, students from diverse majors designed, built, and tested an autonomous vehicle to provide tours to prospective students and their parents. This project involves a multidisciplinary approach with undergraduates and faculty from four different areas: mechanics, mechatronics, industrial design, and computer science.
\end{abstract}

Keywords-Multidisciplinary projects, Automated Guided Vehicle, higher education projects.

\section{INTRODUCTION}

Academic assignments for engineering courses include working on projects that evaluate application of knowledge and skills acquired in the classroom. Despite that this project based approach provides a more comprehensive evaluation compared to exam based courses, there are still shortcomings in this methodology because the projects are constrained to artificial scenarios and isolated from other disciplines. For instance, in [1] researchers compare artificial versus real projects and found that the later has several advantages for both students and educators, while the main disadvantage of academic projects is the lack of interaction with real clients. Also, engineering graduates need to develop strong communication and teamwork skills, and more important, they need to understand how to apply them in practice [2], which cannot be accomplished properly by means of closed academic situations.

Additionally, in some cases, professors feel discouraged to innovate or explore multi-disciplinary projects because of the pressure received to comply with the course syllabus and learning outcomes defined for each program, and time restraints in their course load. Also, educators find challenging the evaluation process that need to be applied in this type of real-world projects [1], where evaluation rubrics need to consider assessment of knowledge, practice and requirement fulfilment.

This work presents the lessons learned from a multidisciplinary project from the inception of the idea thru the

Digital Object Identifier (DOI): http://dx.doi.org/10.18687/LACCEI2016.1.1.380 ISBN: 978-0-9822896-9-3

ISSN : 2414-6390 implementation of the process. During one semester, students from different majors designed, built and tested an autonomous vehicle to provide guided tours inside the campus area to prospective students and their parents. This project involves a multidisciplinary approach with undergraduates and faculty from four different areas: mechanics, mechatronics, industrial design and computer science. Throughout the term, four teams worked to solve different problems from distinct disciplines with the common goal of integrate the solutions to build an autonomous vehicle. This integration took place in several phases to validate and test the compatibility and proper interfaces of the different modules.

The implementation of the project required to tackle several challenges not only faced by the students but also for the professors involved. The mentioned drawbacks cannot be easily addressed entirely to the faculty, but also to administrative staff. Support from the academic leadership, close interaction with administrative departments including finances, registrar's office, media, to mention a few, are vital elements required to increase the chances of success to run a multidisciplinary project as the presented in this work.

The rest of this document is structured as follows. In section II, to put this project in context, background for Project Oriented Learning, focusing on Multidisciplinary projects is given. Section III purpose is to present a brief description of the project expected outcome. In Section IV, an explanation of the design methodology in terms of the academic approach is provided. The purpose of Section $\mathrm{V}$ is to describe the obtained results in terms of a final prototype and, also, the academic outcomes of the project. Section VI contains conclusions and future work.

\section{RELATED WORK}

Project Oriented Learning [3] is used by educational institutions to educate students and evaluate skills acquired in the classroom. In general, projects are divided in two areas: academic or artificial projects, defined by the lecturer; and real projects which are defined by a client with a specific requirement [4]. In the case of artificial projects, there is a consensus that the major drawback is the lack of interaction with real clients [1]. Therefore, to assure that engineering graduates can practice skills for the real world, educators need to design activities that challenge students outside academic scenarios. Furthermore, institutions should provide faculty

$14^{\text {th }}$ LACCEI International Multi-Conference for Engineering, Education, and Technology: "Engineering Innovations for Global Sustainability" 
with the resources (e.g. time, training, money) to create projects with the mentioned characteristics, and additionally, with multidisciplinary teams.

Multidisciplinary projects provide educational institutions and their students a level of immersion in the real world that no other methodology can provide. There are several examples of such initiatives in graduate programs in some universities. For instance, in [5], authors describe how a robot can be created in a course that is shared by some engineering majors. Also, in [6], researchers explain how four engineering courses were coordinated to obtain a final product. Likewise, authors of [7] detail a multidisciplinary approach to create projects with an emphasis in multicultural environments, that is, enable collaboration between participants from different countries. This list is far from being exhaustive, but the focus is mainly on academic projects, nevertheless this is correct if the goal is to teach students how to collaborate in multidisciplinary teams.

\section{Automated GUIDED VEHICLES (AGV)}

An Automated Guided Vehicle (AGV) is an electric powered device able to drive automatically to a designated location with or without cargo [8]. AGVs are widely used in various domains such as storage industry, manufacturing, post office, library, airports, and health services. There are several requirements necessary to work on AGVs that include design, operational and safety factors. Although significant technical advancements have been made since the early days of AGV operation, there are still rooms for improvement particularly in optimizing the operation of large scale AGVs fleet [9].

This paper presents the procedure and lessons learned on a project of designing, building, programming and testing of an AGV. This AGV is designed to provide guided tours inside the university campus to prospective students and their parents. The vehicle must be able to transport up to 4 passengers within the campus area, based on a predefined route as a mean to present the passenger the most relevant spots in the campus.

This project, named Campus Kart, involves a multidisciplinary approach with undergraduates and faculty from four different areas: mechanics, mechatronics, industrial design and information technology. Campus Kart includes two operations modes. The Manual Mode in which the vehicle is controlled by a wireless videogame control and the Autonomous Mode where the vehicle follows a predefined route by using a GPS module.

\section{DeSIGN METHOdOLOGY}

Currently, several universities are encouraging professors to generate innovative and practical capstone projects to emulate working conditions as close as possible to those encountered in industry or research positions [4]. However, there are still in many cases limitations to work in complex and multi-disciplinary projects due to limited budgets, time constraints, and pressure to accomplish specific objectives for each program. The following two sub-sections present the approaches that were used to work on this project from the academic point of view, and from the engineering side.

\section{A. Courses and resources}

In a project where the scope is ambitious, faculty and students must dedicate a considerable amount of resources to reach objectives. In this particular case, students enrolled in up to three courses; in this way, time that is typically spent on sessions, activities and projects, is dedicated entirely to Campus Kart. In most cases, elective courses are used to this end; this decision was made based on the premise that a student's curricula should not be affected in terms of learning outcome for courses which are not related to this project. For those participants that lacked of elective courses, students were mentored to select courses which syllabus is closely related to the project.

With respect to the faculty involved in the project, four professors were assigned with a load of one course per instructor, that is, at least one tutor per knowledge area. This way, they were able to mentor and track progress of students instead of lecture and grade a typical engineering course. Additionally, other two faculty members had a mentoring role in the areas of innovation and product design.

\section{B. Academic approach}

A group of sixteen persons participated in the project of Campus Kart coming from four different disciplines. The four majors involved in this project are Mechanical, Industrial Design, Computer Science and Mechatronics Engineering. Ten students in total participated in the project, were each of them accredited their respective capstone course, and two electives that were registered as research internship. Professors work mainly as mentors, supervising and guiding the students through their project, but also participated as instructors of intensive and short courses, were material normally covered in one term was divided into two to three modules of ten to fifteen hours taught in one week. Additionally, professors and students used online material from MOOCs to complement the required skills and knowledge for the project.

Given the wide range of areas of expertise in a multidisciplinary project, one of the challenges is to establish methods for communication between students and faculty. Similarly, there is the need for a repository where students can exchange ideas, documents and open discussions for a particular topic. As a result of the asynchronous nature of this process, a modified version of the lifecycle model of virtual

$14^{\text {th }}$ LACCEI International Multi-Conference for Engineering, Education, and Technology: "Engineering Innovations for Global Sustainability"

July 20-22, 2016, San José, Costa Rica 
team management developed in [10] was used. In Fig. 1 this process can be observed.

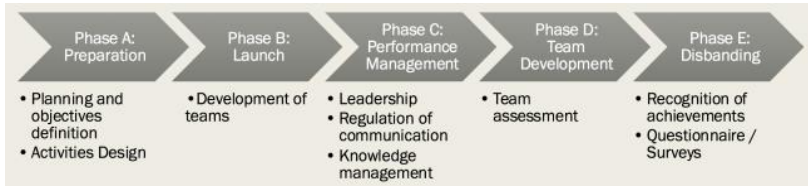

Fig. 1 Team Management

During the Preparation phase, students, faculty and the client gathered to establish project objectives, milestones, limits and exclusions. Based on these requirements, several activities were designed. For the Launch phase, a total of 6 teams were formed: 1 mechanical team, 2 mechatronic teams, 2 with students from Computer Science, and 1 team from Industrial Design. With respect to the performance Management phase, students had specific goals that must be accomplished for a given date; also, for this phase, communication was possible using a technological tool (that will be discussed later) and, to improve face-to-face work, all team members had a physical space in the same facility. Besides, weekly meetings (on site or virtual) were scheduled to assess progress and determine issues that may delay the project. The Team Development phase consisted in training students for specific knowledge using mentoring or via MOOCs. For the last phase, Disbanding, students were recognized in two ways: with outstanding grades for the courses involved and, also, teams were interviewed by the Communications Department to create a documentary on the project.

From an educator's point of view, technology is a great ally, it is fundamental to have tools that allow faculty to follow up activities, discussions and everything that are related to the project [11]. These instruments allow the evaluator to assess student progress during project implementation and also provide means to document the project. From the students' perspective, they must be able to track their progress against a baseline to evaluate different ways of completing tasks and work to finish milestones in time. Notice that this last requirement is essential to any multidisciplinary project since the outcome of a given activity might be the input for another; this implies that the delay on one area may impact the overall project.

There are several tools that can be used to this end such as TeamBox, Basecamp, activeCollage to mention a few. For this project freedcamp, a web-based tool, was used. Freedcamp [12] provides several services integrated in one tool: project management, discussions boards, file management and other tools that can be used to document progress such as Wiki pages. In Fig. 2 a screenshot of the Campus Kart project page in freedcamp is shown. Tracking progress of the activities of the project is a simple but effective endeavor.

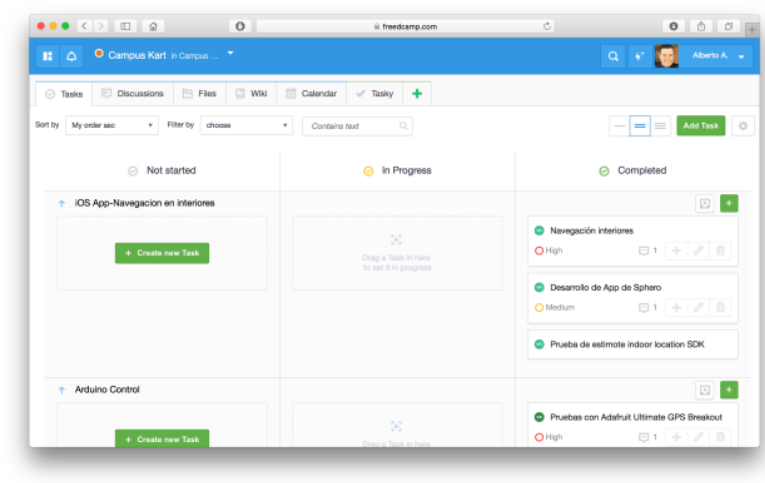

Fig. 2 Project management tool.

This tool was used in several projects before, therefore, students and faculty were familiar with it.

\section{Design for six-sigma approach}

The procedure used to administrate the project was based on the methodology of design for six-sigma [13]. The steps and details for this project are presented below in Table 1.

\section{TABLE I}

\begin{tabular}{|l|l|l|l|}
\hline STEP & ACTIVITIES & MILESTONE & DELIVERABLES \\
\hline DEFINE & Project Definition & $\begin{array}{l}\text { Project } \\
\text { Approval }\end{array}$ & Project Charter \\
\hline MEASURE & $\begin{array}{l}\text { Customer } \\
\text { information, } \\
\text { Conceptual } \\
\text { Design }\end{array}$ & $\begin{array}{l}\text { Product } \\
\text { Approval }\end{array}$ & Proposal \\
\hline ANALYZE & $\begin{array}{l}\text { Value and } \\
\text { Quality Analysis }\end{array}$ & $\begin{array}{l}\text { Product } \\
\text { Optimization }\end{array}$ & $\begin{array}{l}\text { Experimental } \\
\text { Research Results }\end{array}$ \\
\hline DESIGN & $\begin{array}{l}\text { Design } \\
\text { Documentation }\end{array}$ & Prototype & $\begin{array}{l}\text { Prototype and } \\
\text { Engineering } \\
\text { documentation }\end{array}$ \\
\hline VERIFY & Validate Product & Product & $\begin{array}{l}\text { Product and } \\
\text { Report }\end{array}$ \\
\hline
\end{tabular}

\section{RESULTS}

Several aspects of the product are described next to put the scope of the project in perspective, and to understand the required effort. Also, learning outcomes are explained. At the end of the section, lessons learned are given.

\section{A. High-level Architecture}

Due the multidisciplinary approach of the project. The vehicle has been designed using a three-layer approach as seen in Fig. 3.

The first layer (bottom) refers to the mechanical design, the second layer to the mechatronic design and the third layer to the information and communication design. This approach allows that changes in one layer do not interfere with other layers, also, if more functionalities are required, additional layers or additional modules within the layer can be added without affecting the other modules. Mechanical and electronic layers are composed by specific well-defined

$14^{\text {th }}$ LACCEI International Multi-Conference for Engineering, Education, and Technology: "Engineering Innovations for Global Sustainability" 
modules. Each module is independent from the other, and they communicate only through the vehicle main computer. Each module is implemented by an Arduino-Mega microcontroller with sensors and actuators connected as required. The main computer is a Raspberry Pi 2 module which communicate with the Arduinos using USB communication. The communication model is Master-Slave so the main computer (Master) has always the capability to initiate any communication to any slave module.

\section{B. Mechanical Design}

The vehicle has a rear wheel drive and front wheel steering configuration. The final design is shown in Fig. 4. A 48-volt DC motor with an incremental encoder provides the traction in the two rear wheels and another 48-DC motor with an absolute encoder is used for the steering of the two front wheels.

In this project, the focus of the mechanical team was in the design of the structural frame and the steering system. Other students in a previous iteration of the chassis developed the power train system. The braking system was specified but not implemented.

The structural frame was designed based on the outer dimensions defined by the industrial designer's team and validated by the mechanical design team. The focus was in allocating the components and passengers with slightly more weight at the rear axle.

To design the steering system, students and the instructor individually conducted the kinematic analysis of the Ackerman geometry. Due to the many constraints in the implementation of the steering system (lengths of the steering arms and links, stroke of the rack and pinion mechanism, steering angle, space requirements, among others) the final design was obtained after a series of design iterations. The final solution was chosen with two goals in mind: fulfill the requirements, and that the student and instructor agreed on a design that was practical in terms of implementation. This approach has two main objectives; first, having a double check of the calculations and, second, that the student develops the criteria of what is a good practical design and what is not.

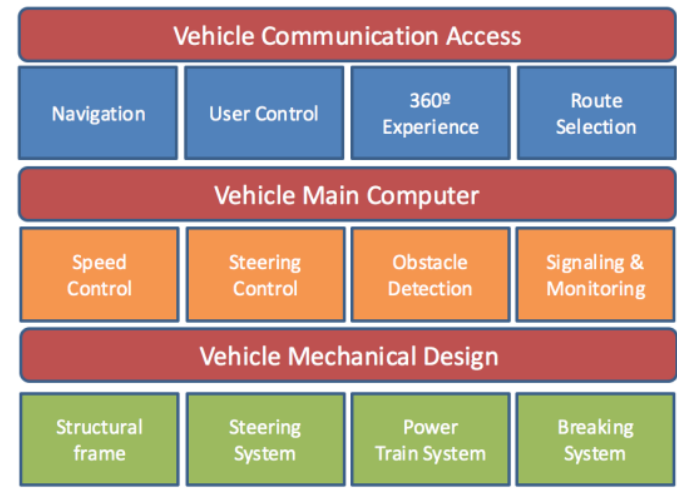

Fig. 3 System Architecture

\section{Navigation Systems}

Typical navigation systems for AGVs include a combination of laser triangulation, inertial, magnetic tape, and magnetic grid. Campus Kart uses a combination of a GPS, a gyroscope and beacons as reference points. The GPS provides the current location by using global coordinates, in addition a gyroscope that measures and maintains the vehicle's course, the beacons are used as reference point embedded in the route at certain coordinates in a map of the system. Vehicle uses feedback from all three devices to determine locations.

\section{Obstacle Detection}

Safety rated laser sensors on the vehicle detect objects in the route path, bringing the vehicle to a safe stop before contacting the obstacle. It uses two signals: one larger warning/slowdown signal and one stop signal. Laser sensor is located at a height of $50 \mathrm{~cm}$. from the floor to detect pedestrians. ANSI B56.5 provides the guidelines regarding vehicle safety [14].

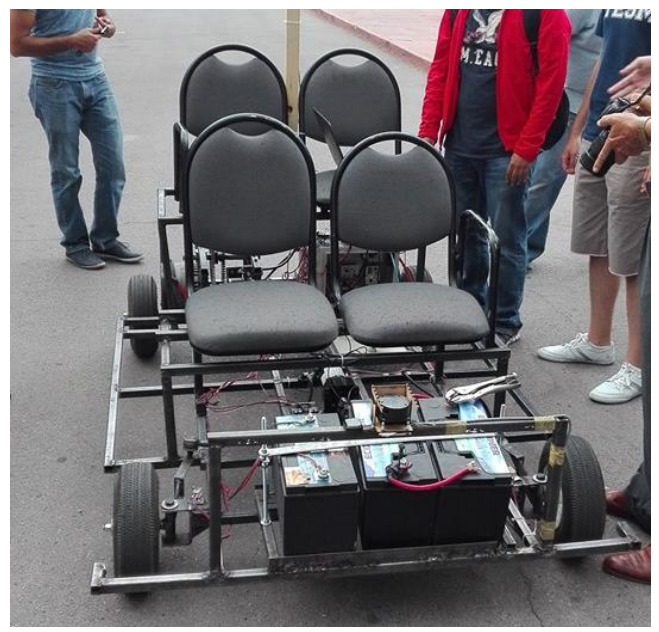

Fig. 4 Prototype of Campus Kart.

\section{E. Vehicle Load and Power}

The vehicle has been designed to transport up to four passengers. The car includes four 12-volts deep cycle batteries

$14^{\text {th }}$ LACCEI International Multi-Conference for Engineering, Education, and Technology: "Engineering Innovations for Global Sustainability" 
in order to provide 48-volts electrical energy for the steering DC motor and the traction DC motor. A separate 12-volt small battery is included to power the electronics components.

\section{F. Scaled prototype}

Given the multidisciplinary nature of this project, several phases ran in parallel. For instance, teams from the mechanics and mechatronics area worked on a real-size prototype while students from computer science built the necessary software to run the car. To this end, a scale prototype was built to test software features, this model can be viewed in Fig. 5. This car is a scaled replica of the real-sized prototype in terms of electronic systems. This is a key factor to build the software that will be used later on the final version: students can test the software API (which is described next) without safety concerns and using a controlled environment prior to the final deployment.

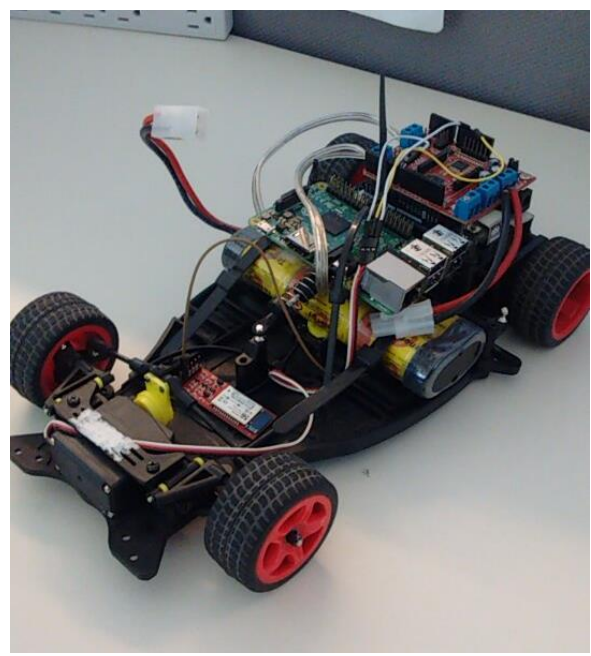

Fig. 5 Scale model to test software features.

\section{G. Software API}

One of the challenges of this project was that Campus Kart should have had two modes of operation to be controlled: a wireless controller or iPad, and an autonomous algorithm. To create a standard software interface for these modes, a software API (Application Program Interface) was designed and built. It can be observed in Fig. 6. Notice that the API is on top of the hardware subsystems and below the mentioned controllers. Using this software and hardware layers, it is possible to create other ways to control the car, for instance a web interface or smart watch application.

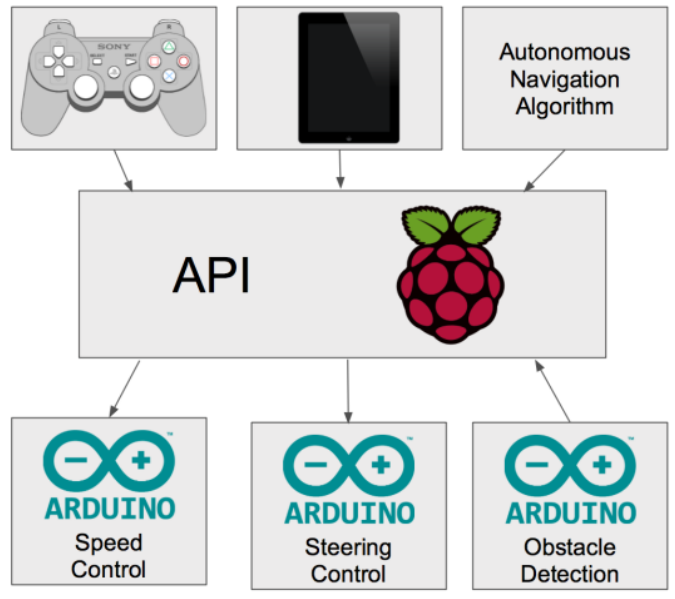

Fig. 6 Software API.

\section{H. Navigation algorithm}

To enable the autonomous operation of Campus Kart, students programmed an algorithm on top of the software API. This algorithm uses a digital compass, a GPS, and an accelerometer to control the car. The approach is straightforward: use the GPS to obtain the vehicle's position and the digital compass to move the steering control in order to travel to a specific GPS coordinate. In Fig. 7, this process is shown. The vehicle adjusts the steering system based on its current position, where it is heading, and the final destination.

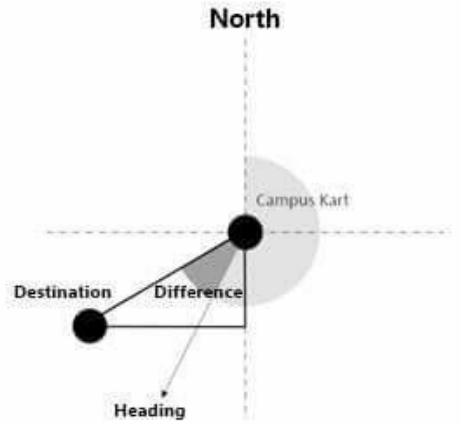

Fig. 7 Adjust direction based on GPS and digital compass.

\section{Learning outcomes}

In a project of this nature, it is difficult to make a quantitative analysis of the learning outcomes. Without any doubt, students completed the given challenge. In general, students were engaged in the endeavor and spent a remarkable amount of time researching, testing and implementing solutions for the unique problems found during the project execution. As part of the feedback, students were asked to turn-in a final report; part of this assignment included a

$14^{\text {th }}$ LACCEI International Multi-Conference for Engineering, Education, and Technology: "Engineering Innovations for Global Sustainability" 
Lessons Learned section. Next, some of the testimonials from the students.

"Without any doubt, this was a specially challenging project, we were introduced to areas of expertise in which we never had been, we had to learn new things on the fly to support the team."

"Fatigue was really hard to fight, but it doesn't compare with the sensation of seeing a successful project in which you've been working on"

"This is the kind of projects that challenge us, and specially, cultivate ourselves"

"We feel proud of being part of this project, we learned how to collaborate in a multidisciplinary team. It is a very different project and allow us to give the best of ourselves"

"The most important thing was the opportunity to apply our knowledge in a real life project, this means that the product that we elaborated will be eventually used by a real customer"

"I learn to work in a team, and I learn to trust in my teammates, I enjoy working with students from other careers since they have different type of working methods and knowledge"

"This was the type of project that I was looking for, since it integrates different aspects from my career, this was an experience that I would never change in my life"

\section{J. Lessons learned}

There are several lessons learned during the design and implementation of this project. It is possible to work with students from different areas with a common goal. When learners are engaged and enjoy working on a project, they make the extra effort to finish tasks exceeding expectations. Nevertheless, most students need mentoring and thus it is important to track progress and monitor the decisions they make during the execution of tasks. The main reason is that they tend to focus excessively on technical issues and might forget functional requirements. Also, educators have experienced with previous projects and their support is invaluable when taking decisions on a high-level design.

Direct contact with the customer. One of the most frequent issues engineering students face when products are designed, is that, the rationale of designing, is focused on the product rather than focused on the user of the product. Young designers tend to focus their efforts on how devices work, how the software will be developed, how the structure will support and protect users, and so on. This is totally acceptable and fine, in fact, it is the most important thing they have to focus on. In other words, the product has to operate perfectly and perform as expected. However, almost as important as the technical capabilities of the device, is the perception and satisfaction of users. Understanding how the user perceives a given product and how the experience of interacting with such a product can be controlled, is a must for engineering students.
Construction of a scaled prototype must be considered a mandatory milestone. It is essential to build a scaled model to test certain features before implementation in the final product. This is helpful for safety and practical reasons. With respect to safety, algorithms were verified in the scaled prototype to assure that software will work once persons are riding the vehicle so debugging will not harm people. From a pragmatic point of view, it is easier to debug in a laboratory inside a facility than testing the vehicle outdoors where heat or cold can be harsh.

Purchases take a while. Educational institutions typically have well-defined process in the procurement department. For this project, there were situations where an electronic component took three months to be delivered after it was ordered. This is a terrible situation considering that one term consists of eighteen weeks only. Purchases must be planned in advance and if possible, consider delays.

Purchase extra components. At some point in the project, one computer science team required to test some features in the full-sized vehicle, however, other teams had to disassemble it to use the mechanical and electronic components in a second iteration. This situation would be easier to handle if students had extra components. Another reason to purchase additional components, is that hardware fail, and it will crash in the most unexpected moment.

Make the project aspirational. One of the reasons for the success of the project is that a selection process was employed. Several weeks before starting the term, students started an application process to be selected. In this manner, inclusion in the project was a choice and not an edict. Using this approach, educators have the opportunity to select the best students.

Develop rubrics to evaluate. Fortunately, milestones were reached, and there is a reason for this: the project was aspirational and only the best students were part of it. However, this would not be the case always. Therefore, educators must have tools to evaluate progress, and students should be aware of these guidelines.

Ask students to ask questions. A term has 18 weeks only; one unanswered question might lead to delays.

Weekly meetings are necessary. As the reader may have noticed, this project was real not only in terms of scope, but also in the way it was executed. A thirty minutes meeting can help to: clarify activities, track progress and interact with the students. If a face-to-face meeting is not possible, make a video conference.

Support from the institution is a key element for the successful execution of this kind of projects. In this particular venture,

$14^{\text {th }}$ LACCEI International Multi-Conference for Engineering, Education, and Technology: "Engineering Innovations for Global Sustainability"

July 20-22, 2016, San José, Costa Rica 
there was plenty of support from the Dean of the School of Engineering, the Center for Faculty Development and Innovation and the Registrar department. Without this help, the project would be unfeasible.

\section{CONCLUSIONS AND FUTURE WORK}

During one semester, students from four different majors worked on an autonomous vehicle, capable of transporting people through specific programmable routes. In this document, the process and the final prototype were introduced as learning approaches to involve undergraduate students in real projects. Three key elements were employed for the design and implementation of this endeavor: a real client with an existent requirement, the interaction of several courses in one project and a multidisciplinary factor. It is quite easy to design a project with two of these characteristics, but to conceive and implement one that has all three is challenging. As part of this paper, lessons learned by faculty can be used as a valuable experience for other educators and institutions as well.

Still, there is plenty of work to do. Our institution has twentyeight campuses across the country, and the central coordination is asking for the construction of thirty additional vehicles to be used in different facilities. This would require sufficient planning and resources.

\section{ACKNOWLEDGMENTS}

Support was received from several people. The Dean of the School of Engineering, which started the project idea and provided support throughout the implementation. The procurement department for making expedited purchases. The Center of Faculty Development and Innovation in Education; they followed the project closely providing mentoring and advice.

\section{REFERENCES}

[1] Clark, N. Evaluating student teams developing unique industry projects, Australasian Computing Education Conference 2005, Newcastle, Australia. ACM, 2005.

[2] Mills,J., Treagust, D., Engineering Education - Is Problem- Based Or Project-Based Learning The Answer, Australasian Journal Of Engineering Education, ISSN 1324-5821, 2003.

[3] Hosseinzadeh N, Reza M., Application of Project-Based Learning (PBL) to the Teaching of Electrical Power Systems Engineering, IEEE Transactions On Education, Vol. 55, No. 4, November 2012.

[4] Clark, N., Evaluating student teams developing unique industry projects, Australasian Computing Education Conference, 2005.

[5] Hassan H., Dominguez C., A Multidisciplinary PBL Robot Control Project in Automation and Electronic Engineering, IEEE Transactions On Education, Vol. 58, No. 3, 2015.

[6] Martinez, M., Romero G., Marquez J., Integrating Teams in Multidisciplinary Project Based Learning in Mechanical Engineering, IEEE EDUCON Education Engineering, 2010.

[7] Fernández M., Conesa D., Hassan H, Multidisciplinary and International Projects, IEEE, 2009.

[8] Yuan, P., Chen, D., Wang, T., Ma, F., Ren, H., Liu, Y., \& Tan, H. (2014, June). AGV System Based on Multi-sensor Information Fusion. In
Computer, Consumer and Control (IS3C), 2014 International Symposium on (pp. 900-905). IEEE.

[9] Schulze L., Wüllner A., The Approach of Automated Guided Vehicle Systems, IEEE, 2006.

[10] Hertel, G., Geister, S., and Konradt, U (2005). Managing virtual teams: A review of current empirical research. Human Resource Management Review, Vol. 15, p. 69-95.

[11] Ahmad N., Laplante P., Software Project Management Tools: Making a Practical Decision Using AHP, Proceedings of the 30th Annual IEEE/NASA Software Engineering Workshop, 2006.

[12]Freedcamp. http://freedcamp.com, 2016.

[13] Hemant V., Kamlapur S., Dhore M., Six Sigma in Education: To Achieve Overall Excellence in the Field of Education, roceedings of the Third International Conference on Information Technology: New Generations, 2006.

[14] ANSI/ITSDF B56.5-2012. Safety Standard for Driverless, Automatic Guided Industrial Vehicles and Automated Functions of Manned Industrial Vehicles. An American National Standard International Truck Standards Development Foundation. http://www.itsdf.org.

$14^{\text {th }}$ LACCEI International Multi-Conference for Engineering, Education, and Technology: "Engineering Innovations for Global Sustainability" 